Florida International University FIU Digital Commons

\title{
The effect of parental and peer attachment on late adolescents' attitudes toward cheating
}

Michael E. Fass

Florida International University

DOI: $10.25148 /$ etd.FI15101352

Follow this and additional works at: https://digitalcommons.fiu.edu/etd

Part of the Psychology Commons

\section{Recommended Citation}

Fass, Michael E., "The effect of parental and peer attachment on late adolescents' attitudes toward cheating" (1996). FIU Electronic Theses and Dissertations. 3285.

https://digitalcommons.fiu.edu/etd/3285

This work is brought to you for free and open access by the University Graduate School at FIU Digital Commons. It has been accepted for inclusion in FIU Electronic Theses and Dissertations by an authorized administrator of FIU Digital Commons. For more information, please contact dcc@fiu.edu. 
FLORIDA INTERNATIONAL UNIVERSITY

Miami, Florida

THE EFFECT OF PARENTAL AND PEER ATTACHMENT

ON LATE ADOLESCENTS' ATTITUDES TOWARD CHEATING

A thesis submitted in partial satisfaction of the

requirements for the degree of

MASTER OF PHILOSOPHY

$\mathbb{N}$

PSYCHOLOGY

by

Michael E. Fass

1996 
To: Dean Arthur W. Herriott

College of Arts and Sciences

This thesis, written by Michael Erik Fass, and entitled The Effect of Parental and Peer Attachment on Late Adolescents' Attitudes Toward Cheating, having been approved in respect to style and intellectual content, is referred to you for judgment.

We have read this thesis and recommend that it be approved.

Jonathan G. Tubman

William M. Kurtines

Mary J. Levitt, Major Professor

Date of Defense: July 17, 1996

The thesis of Michael Erik Fass is approved.

Dean Arthur W Herriott

College of Arts and Sciences

Dr. Richard L. Campbell

Dean of Graduate Studies

Florida Intemational University, 1996 


\begin{abstract}
OF THE THESIS
THE EFFECT OF PARENTAL AND PEER ATTACHMENT

ON LATE ADOLESCENTS' ATTITUDES TOWARD CHEATING
\end{abstract}

by

\author{
Michael Erik Fass \\ Florida International University, 1996 \\ Professor Mary J. Levitt, Major Professor
}

A total of 283 multi-ethnic college students participated in a study investigating (a) the extent to which late adolescents perceived themselves to be attached to parents and peers and (b) the effects of low, medium and high perceived parent and peer attachment on the students' attitudes toward academic dishonesty. Self-report measurements were used in assessing perceived parent and peer attachment levels and the students' tolerance or condemnation toward cheating. The majority of students reported equivalent attachment levels for parents and peers. Contrary to the hypothesis, students reporting low parent attachment and high peer attachment were the least tolerant to cheating. These findings suggest that for late adolescents, low parental attachment without compensatory peer attachment may be a contributing factor in the development of a tolerant attitude toward academic dishonesty 


\section{TABLE OF CONTENTS}

CHAPTER

PAGE

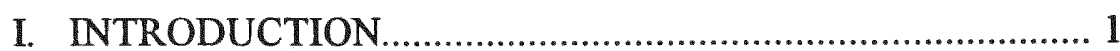

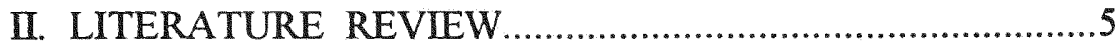

Attachment and Social Support Systems.............................5

Academic Dishonesty..................................................12

III. METHODOLOGY

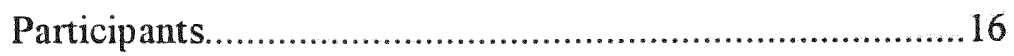

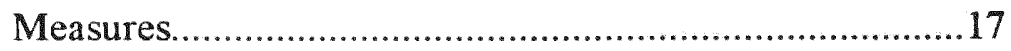

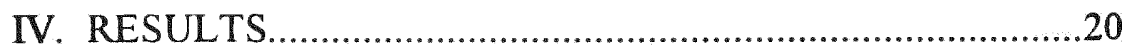

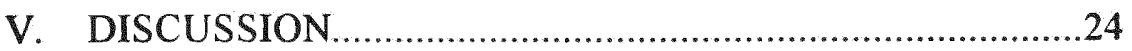

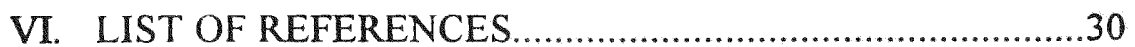

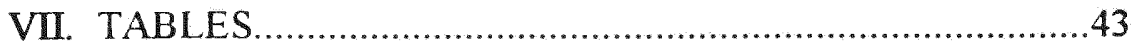

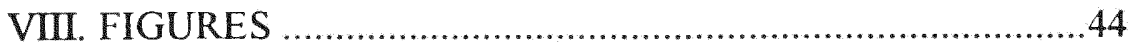

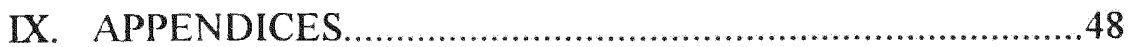




\section{LIST OF TABLES}

TABLE

PAGE

1. Number and Percent of Students at 3 Levels of Parent Attachment by 3 Levels of Peer Attachment.

2. Means and Standard Deviations of ACTS by Attachment Category

3. Correlation Coefficients for Parent Attachment and Peer Attachment and ATCS. 45

4. Multiple Regression of Variables for ATCS. .46 


\section{THE EFFECT OF PARENTAL AND PEER ATTACHMENT \\ ON LATE ADOLESCENTS' ATTITUDES TOWARD CHEATING \\ INTRODUCTION}

As a result of continued research on the nature and importance of attachment relationships across the life span as well as heightened interest in social support systems, a growing number of studies have focused on the influence of parent and peer attachment and support on adolescents' attitudes and behaviors (Armsden, McCauley, Greenberg, Burke, \& Mitchell, 1990; Blain, Thompson \& Whiffen, 1993; Greenberg, Siegel, \& Leitch, 1982; Licitra-Klecker \& Waas, 1993; Nada Raja, McGee, \& Stanton, 1992; Procidano \& Heller, 1983; Sebald, 1989; Wolchik, Ruehlman, Braver, \& Sandler, 1989). Most theories of adolescent development view the time period of adolescence to be psychologically challenging due in part to the normative tasks of separation-individuation and development of a self-identity (Blos, 1967; Erikson, 1958; Lapsley, Rice, \& Shadid, 1989; Youniss \& Smoller, 1985). Parental support and peer support during the salient developmental stage of adolescence are likely to be of great importance to individuals confronted by the transformational tasks associated with adolescence.

Beginning with the research of Bowlby (1973) and Ainsworth (1978), there is now a considerable volume of literature on the function and adaptive value of attachment during infancy and early childhood. During the past two decades, researchers have begun to focus their attention to the role and consequences of attachment on adolescents and young adults. This research has produced several competing views on the degree of attachment between adolescents and parents. The first of these views sees an attachment shift taking place during adolescence, with parental attachment being reduced and peer 
attachment being strengthened. This shift of attachment is seen as part of the striving for autonomy on the part of the adolescent (Steinberg \& Silverberg, 1986). A second viewpoint suggests that attachment patterns do not shift during adolescence. Rather than perceiving attachment as a zero-sum process, this view holds that attachment to same-age peers does strengthen during adolescence but that this strengthening does not come at the expense of parental attachment. Adolescents are viewed as being able to maintain attachment with both parents and peers (Armsden \& Greenberg, 1987; Greenberg et al., 1983; Nada Raja, et al., 1992; Smith, 1976). The life span developmental perspective views adolescent attachment to parents as a continuing process. Peer attachment which develops greater significance during adolescence is perceived as being another level of attachment which does not lead to a diminishing of parental attachment (Troll \& Smith, 1976). One of the aims of this study was to provide additional information on the attachment patterns of late adolescent college students.

Though not all adolescents remain attached to parents, those who do have been found to benefit psychologically on several different levels. Studies have shown strong parental attachment to be positively correlated with an adolescent's well-being (Greenberg et al., 1982), an adolescent's self-esteem (Armsden \& Greenberg, 1987) and an adolescent's social and personal identity (Lapsley, Rice \& Fitzgerald, 1990). Some research has also shown that strong adolescent-parental attachment facilitates the salient developmental process of individuation (Ryan \& Lynch, 1989; Smith, 1976).

Conversely, the research suggests that adolescents who receive or perceive less parental support and greater peer support are at risk for negative psychological effects. There is 
general agreement that excessive peer attachment or influence and low parental attachment is significantly associated with deviant, aggressive, and antisocial behaviors (Cairns, Cairns, Neckerman, Gest, \& Gariepy, 1988; Gillmore, Hawkins, Day, \& Catalano, 1992; Steinberg \& Silverberg, 1986). Although there have been numerous studies on the positive and negative consequences of adolescent-parent attachment, there is limited research on parental or peer attachment effects on an adolescent's moral decisions and specific attitudes relating to ethical issues. This research will shed empirical light on the relationship between parental versus peer attachment and tolerance or intolerance of adolescents' attitudes toward academic dishonesty on college examinations.

The pervasivness and rise of academic cheating on college campuses has received attention in the media during the last decade, but there are only a handful of studies each year that attempt to investigate this behavior from a psychological perspective. Although many students find cheating to be morally wrong, approximately half of all college students have admitted to cheating on at least one examination in college (Bowers, 1964; Maramark \& Maline, 1993). Although the majority of research literature on academic dishonesty has focused on situational determinants and dispositional determinants of cheating, there is limited research on the possible determinants of one's peer group or social support network on academic dishonesty (Baird, 1980; Davis, Grover, Becker, \& McGregor, 1992; Enker, 1987; Lanza-Kaduce \& Klug, 1986, Michaels \& Miethe, 1989). With academic dishonesty in college becoming an ever increasing problem for college administrators, faculty, and students, this study will research the effects of parental and peer relationships on a college student's tolerance or condemnation 
of academic cheating. This study was designed to show that late adolescent college students who perceive themselves to be more peer attached than parent attached will demonstrate a more tolerant attitude toward cheating than either a more parent attached late adolescent or a late adolescent attached to both peers and parents. There were two specific aims.

\section{To determine the extent to which late adolescent college students perceive} themselves to be attached to parents versus peer. Based on previous research, it was hypothesized that the majority of participants would not show a pattern of diminished attachment to parents compared to peers. It was also hypothesized that the majority of participants would perceive themselves to have parent and peer attachment levels that are somewhat equivalent. The literature suggests that a minority of the participants should be expected to be classified as low on parental attachment and high on peer attachment (Armsden \& Greenberg, 1987; Licitra-Kleckler \& Waas, 1993).

2. To determine whether the low parent-high peer classification is predictive of a pro-cheating attitude among late adolescent college students. It was hypothesized that participants in the low parent-high peer category would have a greater tolerance to cheating than the other three categories: high parent-high peer, high parent-low peer, and low parent-low peer. These results extend the findings of previous studies which found a correlation between an individual's attitude toward cheating and his-her peers' attitude toward cheating (Bonjean \& McGee, 1965; Lanza-Kaduce \& King, 1986). 


\section{LITERATURE REVIEW}

\section{Attachment and Social Support Systems}

The marrow of the attachment theory is that meaningful social attachments, especially between child and parent, are crucial to the overall psychological well-being of the individual (Bowlby, 1973; Ainsworth, Blehar, Waters, \& Wall, 1978). Bowlby's ethological theory of attachment views attachment as an enduring affective bond that provides security and promotes the development of various competencies including social, intellectual, and psychological as well as promoting adaptive environmental functioning (Kenny \& Donaldson, 1991). Initial attachment dyads are considered to be psychologically significant since it is the initial attachment experiences that set the foundation for social expectations of future attachment relationships (Levitt, Coffman, Guacci-Franco, \& Loveless, 1993). Due to repeated interactions with the mother(or primary caregiver), the child develops "internal working models" about self, significant others, and the larger social world. These internal working models or cognitive representations of this early relationship acts as a prototype for future attachment relationships. (Bowlby, 1969; Bretherton, 1985; Rothbard \& Shaver, 1994). Deficiencies in attachment during the formative years may produce insecure behavior patterns and failure to thrive. Early attachment problems are also hypothesized to have a negative effect on attachment relationships in later life(Bradford \& Lyddon, 1995; Gewirtz, 1968; Kobak \& Sceery, 1988; Sroufe, 1983). Inconsistent, ambivalent, or negative attachment relationships with a parent may also leave children and adolescents vulnerable to 
dysphoric states (Bategos \& Leadbetter, 1994) as well as other developmental disorders.

Although much has been studied and written about the Ainsworth-Bowlby conceptualization of attachment as it relates to infancy and early childhood, there is growing interest in attachment relationships beyond childhood and into adolescence and adulthood (Bartholomew \& Horowitz, 1991; Brennan, Shaver, \& Tobey, 1991; Bretherton, 1985; Collins and Read, 1990; Greenberg et al., 1983; Hazen \& Shaver, 1987; Kahn \& Antonucci, 1980; Levitt, 1991; Weiss, 1982). The life-span perspective on attachment suggests attachment plays a crucial role at all ages and that attachment across the life span results in numerous psychological gains for the individual. Greater self-esteem and social bonding capabilities are examples of psychological benefits produced by attachment at various developmental stages (Bell, Avery, Jenkins, Feld, \& Schoenrock, 1985; Kalish \& Knudtson, 1976). The literature suggests that attachment relationships between parent and child may vacillate for both parent and child at particular developmental stages, but these initial attachments are likely to continue across the individual's life (Antonucci, 1990; Hagestad, 1984; Levitt, 1991; Takahashi, 1990). For most individuals, the parent-child relationship appears to be a permanent though evolving process across the life-span.

Recent studies on attachment between adolescents and parents have indicated that most adolescents maintain a strong attachment to their parents (Armsden \& Greenberg, 1987; Collins \& Read, 1990; Greenberg et al., 1983). Nada Raja et al. (1992) found adolescents to be highly attached to both parents and peers, suggesting that attachment to peers does not come at the expense of attachment to parents. This study also found 
attachment to peers to be qualitatively different from attachment to parents, in support of Berndt's (1979) independent "social worlds" perspective. Although certain groups of adolescents were not found to be attached to parents, Armsden \& Greenberg (1987) found the majority of adolescents to be strongly attached to parents and this attachment was. significantly related to psychological well-being among adolescents. This research supports Ainsworth's (1989) belief that attachments are not limited to a parent or a caregiver but attachments can be formed with several individuals including peers and siblings and these attachments can take place across the life span.

Previous studies have not only shown adolescents to remain attached to their parents while also developing new attachment to peers; these studies have also revealed that, for the majority of adolescents, attachment levels to parents and peers are somewhat equivalent in strength (Armsden \& Greenberg, 1987; Lictra-Klecker \& Waas, 1992). Adolescents who reported being highly attached to parents usually also reported being highly attached to peers or having at least a moderate attachment to peers. Only a minority of adolescents reported attachment between parents and peers that was lopsided in naturelow parent to high peer or high parent to low peer. This equivalent attachment pattern suggests that most adolescents develop peer attachments to a magnitude similar to the magnitude of their parental attachment. In many ways, this is supportive of the theories of internal working models. One of the goals of this study is to provide additional information concerning late adolescent college students' "convergent pattern" of attachment to parents and peers.

Studies of life span attachment relationships have become interrelated to research and studies of the significance of social support systems, social support networks, and social 
support convoys. Blain et al., (1993, p. 228) have suggested that social support systems "may be an observable manifestation of attachment styles." Research has shown that individuals scoring high on attachment ratings also score high on social support ratings (Blain et al., 1993). Some theorists have proposed that attachment relationships form a part of or become a specialized subset of the social support network. (Antonucci, 1990; Levitt, 1991; Takahashi, 1990). Similar to attachment shifts, social support systems during particular age-related developmental stages also show evidence of transitory fluctuations between family and friend (Bergston, Rosenthal, \& Burton, 1990; Levitt, Weber, \& Guacci, 1993). The literature suggests that social support networks are ongoing relationships which manifest elements of both change and continuity (Levitt, 1991).

A large body of social support literature has shown that social support networks facilitate psychological well-being by providing the individual with informational support, affective support, and affirmational support (Antonucci, 1990; Kahn \& Antonucci, 1980; Levitt, 1991; Licitra-Kleckler \& Waas, 1993). A similar division of support categories was found by Cohen and Wills (1985). Their support components were divided into esteem support, instrumental support, informational support, and social companionship. Schulz and Rau (1985) found that for young adults, friends became the major source for informational and emotional support while parents provided tangible aid. Numerous studies have shown that people who maintain support networks are in better physical health, better able to handle stress, and more mentally healthy than individuals with weak social support networks (Antonucci, 1990; Cohen \& Wills, 1985; Holahan \& Moos, 1981). 
A current trend in social support system research is the distinction being formulated between objective characteristics of support networks and perceived social support. Objective network characteristics support include size, density, proximity and other related structural elements of the support system, along with the actual support perceived by the network. Perceived social support refers to the psychological and supportive impact the structural system has upon the individual (Blain et al., 1993; Heller \& Swindle, 1983; Licitra-Kleckler \& Waas, 1993; Procidano \& Heller, 1983.) Perceived social support, as well as perceived attachment, is based on the individual's perception that his/her support needs are being satisfied by parents, peers, or other support group members. There is limited research on the identification of differences between what is perceived to be available and what is actually available (Winemiller, Mitchell, Sutliff, \& Cline, 1993), but perceived support has been shown to relate to personal well-being more than mere objective indicators of support (Antonucci, 1990). Several studies have suggested that individuals who perceive their support to be adequate to cope successfully with their needs will be more likely to cope with stressful events (Cohen \& Wills, 1985; Heller \& Swindle, 1983).

Although social support networks have usually been defined as leading to positives outcome for the supported individual, a negative effect from supportive behaviors is also a possible outcome. A distinction needs to be made concerning the positive intent of the 'supporter' versus the possible negative outcome for the 'recipient'(Antonucci, 1990; Heller, 1979; Levitt, Silver, \& Guacci-Franco, 1993). 
Negative effects of social support Having been mostly ignored by researchers investigating the positive effects of attachment and social support networks, the negative side of social interaction has been slowly gaining attention. Social relationships rarely are all positive or all negative and social exchange theorists had already pointed out that social relations entail costs as well as rewards (Homans, 1974; Thibaut \& Kelly, 1959). Overprotection, reinforcement for negative behaviors, or assistance given on demeaning terms are possible maladaptive consequences of social networks (Antonucci, 1990). Thus, even concerned and supportive networks may produce negative consequences. The limited research on the negative effects of social networks has focused on the maladaptive effects upon the individual (Rook,1984; Cairns et al., 1988). Research on the negative effects of attachment and social networks on a social level has yet to be fully addressed. This study is based on the perspective that academic dishonesty is a negative outcome of high peer attachment and that academic cheating not only has a potentially maladaptive effect on the individual but that academic dishonesty or a tolerant attitude toward cheating behaviors has a tremendous negative impact on society.

Although numerous studies have shown peer rejection to be a salient correlate to maladaptive disorders among adolescents (Boiven, Hymel, \& Bukowski, 1995; Coie, Lochman, Terry, \& Hyman, 1992; Kupersmidt, Burchinal, \& Patterson, 1995), Cairns et al. (1988) studied whether highly aggressive adolescents who usually tend to be peer rejected, became members of definable social networks or social clusters, the extent of social support for aggressive behaviors among these adolescents, and whether there were significant gender differences. The results showed both highly aggressive males and highly 
aggressive females were members of social networks and these networks promoted aggressive behaviors through the processes of reciprocity and the contagious nature of aggressive behaviors. Studying elderly widowed women, Rook (1984) examined the positive and negative social outcomes of social support systems. The results of this study indicated that positive and negative social support represent two independent domains of experience and that problematic social ties had a greater effect on well-being than positive social ties. Likewise, studies finding troublesome relationships within social networks among university students and employees (Levitt, et al., 1993) and emotional overinvolvement of members in social networks (Coyne, Wortman, \& Lehman, 1988) are supportive of the negative side effects related to attachment and social support networks. This study attempts to determine whether tolerance to academic dishonesty by late adolescent college students is a by-product of peer social support.

Family and Peer Attachment and Support Prociadno \& Heller (1983) studied the social support of family and peers to college students and found that perceived social support is related to certain personality traits and may be influenced by affective states. Perceived family support systems were found to be generally more stable than peer support systems. Perception of family support was also shown to be less affected by the mood states than the perception of peer support. Licitra-Kleckler \& Waas (1993) found that adolescents who perceived high family support were better able to deal with stressful events and also tended to exhibit fewer delinquent behaviors than adolescents who perceived low family support. Perceived family support was assessed to have a broad influence on the psychological and social adjustments on adolescents whereas perceived peer support was associated with less depression and greater self-esteem. Perceived social 
support from friends and family and strong attachment to friends were found to be related to positive working models of self and others in a study of late adolescents whereas insecure attachment was associated with lower perceived social support from both friends and family (Blain et al., 1993).

Although the focus of attachment theory research continues to be childhood attachment, with an emphasis on the dyadic relationship between mother and child, there is a widening interest in the attachment of late-adolescents college students (Kenny, 1990; Kenny \& Donaldson, 1991, 1992). Previously, college years have theoretically been regarded as a developmental time period of parental separation, gained autonomy, and identity formation (Arnstein 1980; Chickering, 1969). Recent research shows strong attachment between late adolescent college students and parents fostering competence, psychological adjustment, stress coping, and career development among the late adolescent students(Bell et al., 1985; Blain et al., 1993; Blustein, Walbridge, Freiedlander, \& Palladino, 1991; Brack, Gay, \& Matheny, 1993; Hays \& Oxley, 1986; Maurer, 1982; Lapsley et al., 1990). These studies support the life-span perspective that views attachment continuity as a pattern beginning in childhood and evolving into late adolescence. Ryan \& Lynch (1989) in their "revisiting the vicissitudes of adolescence and young adulthood" article, theorize that attachment, not detachment, to parents during the adolescent-young adulthood time period optimizes individuation and identity growth.

\section{Academic Dishonesty}

Over the past two decades, academic dishonesty or academic cheating has been increasing among high school and college students and has become a serious problem on 
most college campuses (Davis \& Ludvigson, 1995; Fishbein, 1993). With studies indicating that $40 \%$ to $60 \%$ of college students cheat on at least one examination during their college years, it is not surprising that academic dishonesty has generated attention from the social science community as well as the national media (Jendrek, 1992; Schab, 1991). Much of the research on academic dishonesty has concentrated on the relationship between morality and cheating (Corcoran \& Rotter, 1986; Lanza-Kaduce \& Klug, 1986; Leming, 1978) and situational determinants such as exam difficulty (Winston, 1975; Haines, Diekhoff, LaBeff, \& Clark, 1986) and seating arrangements (Vitro, 1969; Houston, 1976). Stevens (1984) found students considered cheating to be unethical but still necessary to compete successfully in school. Students in this study who admitted to cheating believed their peers also cheated and perceived themselves to be more ethical than their peers. Lanza-Kuduce \& Krug (1986) found college students at lower developmental levels of morality were influenced by their peers to cheat on examinations, whereas peer influence was not significant for students at the middle or high moral developmental levels.

More recently, investigations into why individuals cheat in college or develop a tolerance to college cheating have focused on the relationship between personality traits and academic dishonesty. Haines et al.(1986) identified student immaturity and lack of commitment to academic studies as dispositional factors that contributed to cheating behaviors. Several studies have examined the connection between Type A and Type B personalities and cheating behaviors with somewhat inconclusive results (Huss, Curnyn, Roberts, \& Davis, 1993; Perry, Kane, Bernesser, \& Spicker, 1990). Research on the effects of locus of control on cheating behaviors (Karabenick \& Scrull, 1978) and the 
relationship between self-monitoring and cheating (Covey, Saladin, \& Killen, 1988) have also produced inconclusive results.

Research literature on academic dishonesty has shown that a student's attitude toward cheating and cheating behaviors are enhanced or impaired by the student's social environment of friends and peers. Students who rated high on a social alienation scale were found to be more likely to cheat than less alienated students (Calabrese \& Cochran, 1990). Several studies have shown that a student's probability to cheat is reduced if the student perceives that his/her friends and peers have a negative regard for cheating (Bonjean \& McGee, 1965; Bowers, 1964; Liska, 1978). Michaels and Miethe (1989) theorized that, based on Hirschi's social bond theory of deviant behavior (1969), cheating behaviors should be positively associated with attachment to peers and friends who engage in cheating. Michaels \& Miethe found that adolescent-aged students who believed their friends to be supportive and tolerant of cheating behaviors as an acceptable means of achieving academic success were much more likely to be tolerant of cheating as well as to have taken part in more cheating behavior. Peer pressure to cheat and perception of friends' attitudes toward cheating were found to be factors leading to academic dishonesty behaviors (Bonjean \& McGee, 1965; Calabrese \& Cochran, 1990).

The literature suggests a strong link between perceived attitude toward academic dishonesty by one's peers and friends and a greater tolerance or acceptance of academic dishonesty by college students. Although previous studies have focused on certain peer influences on academic dishonesty, the influence of the parent bas been noticeably absent. The results of this study were expected to show that late adolescent college students who 
are more peer attached will have a greater tolerance to academic dishonesty than students who are more parent attached. 


\section{METHOD}

\section{Participants}

Respondents in this study were 283 college students attending during the fall and winter semesters of the 1995/1996 year. Participating students were enrolled at two universities and one community college in Dade County, Florida. Among the participants were 90 male (31.8\%) and 193 female (68.2\%) students ranging from age 17 to $25(\mathrm{M}=$ $19.72, \mathrm{SD}=1.89$ ). The ethnic make-up of the participating students was 29 EuropeanAmerican (10\%), 89 African-American (32\%), 134 Hispanic-American (48\%), with 29 classified as Other ( $10 \%$, comprised of students from Asia, India, Pakistan, or the Middle East). The majority were first or second year students (75\%) with juniors and seniors making up the remaining $25 \%$. A small percentage of students belonged to a Greek fraternity or sorority $(5.7 \%)$, most were unmarried $(94.7 \%)$, and due to the urban commuter setting of these universities, $75.5 \%$ of the students lived at home with one or more parent. Based on the Entwisle \& Astone (1994) Socioeconomic Status scale, the median occupational status of the father was 52 with a range of 0 (not employed, $5.3 \%$ ) to 97 (physician, .4\%). The median occupational status for the mother was 59 with a range of 0 (not employed, $7.1 \%$ ) to 97 (physician, .4\%).

Upon consenting to participate in the study, respondents were given a Student Survey form and the Inventory of Parent and Peer Attachment (IPPA) with half the students receiving the peer questionnaire first and the other half receiving the parent questionnaire. A three-digit identification number was assigned to each respondent. Respondents were told that they had completed the first half of this study and that names 
and addresses of a best friend and significant parent needed to be brought to class in one week. On the second visit to class, respondents were asked to complete the Attitude Toward Cheating Scale(ATCS) and also to address envelopes to parent and best friend (peer), so that the friend and parent could be sent the ATCS which would be returned in a self-addressed envelope. They were also asked to write their identification code on each envelope. Chi-square and T-test analyses showed that no differences were found due to the counter-balancing of the attachment measures. Of some 150 forms of ATCS sent to both parents and friend, less than $10 \%$ were returned. Consequently, it was not possible to conduct analyses including these data.

\section{$\underline{\text { Measures }}$}

Inventory of Parent and Peer Attachment (Appendix A). Attachment levels were assessed using the Inventory of Parent and Peer Attachment (IPPA) developed by Armsden and Greenberg (1987). This two part assessment is a self-report questionnaire that measures the cognitive and affective quality of parent and peer attachment in late adolescents and young adults. It includes subscale scores for trust, communication, and alienation. The IPPA is based on the assumption that parental attachment is a source of continuing psychological well-being for adolescents and young adults while significant peers begin to serve as important attachment figures as well (Lopez \& Gover, 1993). Two separate attachment scores, parental and peer, are calculated by adding the trust and communication scores and then subtracting the alienation score. The IPPA has been used successfully in numerous studies (Armsden \& Greenberg, 1987; Blain et al., 1993; Lapsley et al., 1990; Nada Raja, et al., 1992; Palladino \& Blustein, 1991; Quintana \& Lapsley, 
1988). Responses were based on a 5-point Likert scale. Response categories were Almost Never or Never, Seldom, Sometimes, Often, and Almost always or Always. Negatively worded statements were later recoded. Higher scores show stronger attachment to parent and peer. The internal consistency coefficients of this instrument have been reported to be in the $.90 \mathrm{~s}$. The authors of this measurement report Cronbach's coefficients alphas for the Parent scale to be .91 for the Trust factor, .91 for the Communication factor, and .86 for the Alienation factor. Alphas for the Peer scale were .91 for Communication, .87 for Trust, and .72 for Alienation. Three-week test-retest reliability coefficients were .93 for the Parent Attachment Scale and .86 for the Peer Attachment Scale(Armsden \& Greenberg, 1987). Alpha coefficients for the Parent Attachment Scale for the present study were .89 for Trust, .89 for Communication, and .84 for Alienation. The Peer Attachment Scale's alpha coefficients for this study were .88 for Trust, .83 for Communication, and .65 for Alienation.

Attitude Toward Cheating Scale (Appendix B). The Attitude Toward Cheating Scale (ATCS) was designed and tested by Gardner \& Melvin (1988) to measure positive and negative attitudes toward cheating by college students and faculty. This instrument was recently used by Roig \& Neaman (1994) in a study on cheating and alienation. This questionnaire has been found to have adequate construct validity and an adequate splithalf reliability was obtained by correlating the total odd and total even item scores and correcting $r$ with the Spearman-Brown formula. A correlation of $-.30(\mathrm{p}<.05$, onetailed) between the ATCS and actual mean cheating rates of students was obtained (Gardner \& Murphy, 1988). Responses were based on a 5-point scale ranging from 
Strongly agree $(+2)$ to Strongly disagree $(-2)$. Higher overall test scores indicate a condemnatory attitude toward cheating while low scores indicate a more tolerant attitude toward cheating. Participants completed the ATCS approximately a week after completing the IPPA. The alpha reliability of the scale for the present study was .67. 


\section{RESULTS}

Scores for late adolescent student perceptions of their attachment relationships with parents and peers were obtained through the use of the IPPA. Similar to Armsden \& Greenberg's (1987) categorization (though a combined subscale was used in this study), the score distributions for the student participants were divided into three groups (low, median, high) for both parent and peer attachment.

A chi-square analysis of the distribution of students' scores across the parent and peer attachment categories (Table 1) was significant : $\chi^{2}(4, \underline{N}=283)=32.47, \underline{p}<.0001$. These results are consistent with previous studies of adolescent attachment patterns (Armsden \& Greenberg, 1987; Sebald, 1993). As anticipated, the vast majority of adolescents were found to have either convergent parent and peer attachment patterns categories $(42 \%$, low-low, medium-medium, or high-high) or greater parent than peer attachment (30\%). These results suggest that about three-fourths of these late adolescents showed parental attachment levels that were at least equivalent to the level of peer attachment. Only $28 \%$ of these students were found to be more attached to peers than to parents. Interestingly, only $12 \%$ of these students revealed markedly divergent attachment levels(low-high or high-low) for parents and peers.

One-way analyses of variance of parent and peer attachment scores yielded no differences in parent or peer attachment based on residency (living at home with parents or not living at home with parents), or gender, but ethnic differences were found for both 
parent attachment, $\underline{F}(3,277)=10.96, \underline{p}<.0001$ and peer attachment $\underline{F}(3,277)=7.87$, $\mathrm{p}<.0001$ The European-American students $(\mathrm{M}=64.31, \mathrm{SD}=14.76)$ were found to show significantly more parent attachment than the group of African-American students $(M=46.61, S D=21.05)$. Parental attachment for Hispanic-American students $(M=57.59, \mathrm{SD}=18.11)$ was also significantly different from the African-American students. Ethnic differences also were revealed to be significant for the peer attachment scores. European-American students $(M=69.76, S D=8.16)$ showed a significantly higher mean score than both Hispanic-American students $(M=60.81, S D=13.16)$ and African-American students $(\mathrm{M}=57.73, \mathrm{SD}=11.1)$ A one-way analyses of variance on the ATCS by ethnicity revealed no significant differences among the various student ethnic populations.

To address the relation between parent-peer attachment and tolerance of cheating, an analysis of variance of scores on the ATCS was conducted with gender as a between groups factor and parent and peer attachment category (high, medium, low) as a within groups factor. There was a significant interaction of parent and peer attachment categories, $\underline{F}(4,263)=2.55, \underline{p}<.04$. Means and standard deviations are presented in Table 2. Post-hoc Student-Newman-Keuls analyses at each level of parent attachment indicated that there were significant peer attachment differences only in the low parent attachment group. Contrary to the proposed hypothesis, the low parent/high peer attachment group showed less tolerant attitudes toward cheating, whereas those with low parent attachment and low to moderate peer attachment were the most tolerant of cheating. These results are presented in Figure 1.

The correlations of the attachment summary and subscale scores with the attitude 
toward cheating scale are presented in Table 3 . Although the correlations of the attachment summary score and the trust and communication subscales with the ATCS were not significant, the parent alienation subscale was significantly related to the ATCS scores $(\mathrm{p}=.04)$ and the peer alienation subscale was marginally significant $(\mathrm{p}=.07)$. These results suggest that degree of perceived alienation may play a crucial role in influencing a late adolescent student to be more tolerant to cheating.

Table 4 presents the results of a multiple regression analyses for the attitude toward cheating scores. The purpose of this analysis was to determine the extent to which students' attachment category was related to tolerance of cheating over and above potentially relevant demographic predictors. Demographic predictors including residency (living at home or not living at home),place of birth (United States vs. other), ethnicity (represented as two dummy coded variables, $1=$ European -American, $0=0$ ther and $1=$ Hispanic-American, $0=$ other) were entered first in this analysis followed by three dummy-coded variables representing the attachment category levels of interest (low parent vs. other, high peer vs. other, and low parent, high peer vs. other). For the low parent variable, students in the low parent category were assigned a score of 1 and those in the medium and high categories were assigned a score of 0 . For the high peer variable, students in the high peer attachment group were assigned a score of 1 versus 0 for the medium and low peer attached groups. The low parent-high peer variable was created by assigning a score of 1 to students classified as both low in parent attachment and high in peer attachment and a 0 was assigned to those students in all other categories. The results of this multiple regression analysis revealed no significant effects for residency and 
ethnicity. Gender and country of birth were related to a marginal degree. However, both low parental attachment and the low parental attachment - high peer attachment combination were related significantly to attitude toward cheating scores. This analysis suggests that low parental attachment contributes to a more tolerant attitude toward cheating, whereas low parent attachment combined with high peer attachment fosters a less tolerant attitude to cheating. 


\section{DISCUSSION}

The results of this study provide additional information on the attachment relationships of late adolescent college students to their parents and peers. However, while the results do contribute to the understanding of some factors relating to a late adolescent's tolerant or intolerant attitude toward cheating, the expectation that high parental attachment coupled with low peer attachment would lead to a less tolerant attitude toward cheating was not supported in this study.

As expected, late adolescent college students reported attachment levels for parents and peers which suggest that late adolescent students maintain their attachment to parents even when they develop attachment to peers. The majority of late adolescent college students' levels of attachment for parent and peer were somewhat comparable. In fact, most of this sample of late adolescents were equivalent or near equivalent in parent and peer attachment categories. These findings are consistent with the previous studies which have found a minority of their participants to have divergent parent and peer attachment relationships: low-high or high-low (Armsden \& Greenberg, 1987; Nada Raja et al., 1992). This finding of "convergent attachment" is similar to what Youniss \& Smollar (1985) described in discussing parent-child attachment becoming less asymmetrical during late adolescence and reminiscent of Furman \& Buhrmester's (1992) description of parent-child relations becoming more egalitarian in late adolescence.

These results might suggest that moderate to positive attachment relationships with parents lead to moderate to positive attachment to peers. This is consistent with internal 
working model theories and the life span perspective on attachment styles (Bretherton, 1985; Main, Kaplan, \& Cassidy, 1985). Although the majority of the literature points to a positive parental attachment fostering positive peer attachment, this does not negate the possibility that in some cases positive peer attachment fosters or rekindles positive parent attachment. These data are also generally supportive of Bowlby's overall thesis (1969) that parent attachment is enduring unless a major experience of discontinuity takes place.

The present findings reveal a significant difference for both parent and peer attachment across various ethnic student populations. European-American students perceived themselves to be attached to both parents and peers to a greater degree than any other ethnic group in this study. Ethnic ranking for parental attachment in descending order was European-American students, Hispanic-American students, and AfricanAmerican students. In descending order, a similar pattern of peer attachment was found: European-American students, Hispanic-American students, African-American students. These findings of ethnic differences contradict Armsden \& Greenberg's (1987) findings that showed no significant differences between Caucasian and non-Caucasian adolescents. Continued research into this ethnic difference may clarify whether the findings of this study are due to differences in the quality of parent-peer relations or subtle cultural differences in attachment patterns and attachment needs. It may also be that the IPPA is less appropriate as an attachment measure for the non-European-American students in this study. The heterogeneity of each of these groups needs to be emphasized at this time. The families of Hispanic-American students in South Florida include immigrants from Cuba, Nicaragua, and other South American and Central American countries, whereas the 
families of African-Americans include those born in the United States and immigrants from Haiti, and other Caribbean nations.

The primary goal of this study was to use attachment levels to parents and peers as predictors of a student's attitude toward cheating on academic examinations. Contrary to expectation, students with low parent attachment and high peer attachment reported a significantly less tolerant attitude toward cheating. Several explanations are possible for this finding.

There are two issues of measurement that may be relevant. First, the ATCS was chosen for this study because it was the only cheating measurement that focused on the moral issue of academic dishonesty. Unfortunately, for this study, the ATCS was shown to have a low reliability coefficient, which suggests that this measurement is not as sound as it needs to be to detect attitudes toward cheating. Some of the statements on the ATCS are clearly worded toward a specific condemnation or tolerance to cheating such as "Cheating on college tests is morally wrong" and "Most students who cheat are unethical people". However, several ambiguous statements may cause the respondent to give prostudent responses which may be interpreted as an anti-cheating response. Statements such as "If during a test one student is looking at another student's answer sheet, the teacher should not point this out because it might embarrass the student" and "A student who sees another student cheating and reports it should refuse to identify the cheater" may easily be interpreted by student respondents in ambiguous and misleading ways. Perhaps a refinement of the ATCS is in order or a more morally specific, less relationship oriented questionnaire needs to be developed. Another measurement related explanation may have 
to do with the small size of the low parent/high peer group( $n=16$ or $6 \%$ of the total student sample) although there were no specific outliers in the group.

It is also possible that these findings reflect accurately the relation between parent and peer attachment and tolerance for dishonesty. If so, the results suggest that medium to high parent attachment acts to promote less a deviant attitudes regardless of the student's level of attachment to peers. However, if the student perceives a low level of parental attachment, high peer attachment may provide a compensatory buffering effect. Students in the low parent - low peer group were most tolerant of cheating. This finding is consistent with much of the literature on peer-rejected adolescents. There is a strong likelihood that low peer attached adolescents did not choose to be so low attached, but were rather rejected by their peer group. Peer rejection during childhood, early adolescence or late adolescence seems to mediate a developmental trajectory toward deviant peer groups which in turn increases the chances for antisocial behavior (Coie, Lochman, Terry, \& Hyman. 1992; French, Conrad, \& Turner, 1995) Having the least attachment of all the other groups to either parent or peer, individuals would be expected to be less concerned over the moral issues related to cheating and other socially normative behaviors. This finding is consistent with Lictra-Klecker \& Waas' (1993) study which found male and female adolescents who combined low family and low peer support were more likely to be involved in various delinquent activities. One would expect this group to be alienated from both parent and peer and this may be reflected in the significant subscale correlation of alienation from parent and a tolerant attitude toward cheating and a marginally significant subscale correlation between alienation from peers and a tolerant attitude toward cheating. Since the subscales of trust and communication were not 
predictive, more research on the relation of perceived alienation of late adolescents to moral attitudes and behaviors should be considered.

Although this study has contributed to the understanding of parent and peer attachment among late adolescent college students as well as having provided exploratory findings on the relationship between attachment and attitudes toward cheating, limitations of this research should be noted and considered for future research. By focusing on late adolescent college students, the participants in this study were goal-oriented and selfdirected individuals whose attitudes on cheating and other issues might be less influenced by parents and/or peers. Perhaps a study using middle school or high school students might show a peer attachment effect on the child's attitude toward cheating more so than late adolescents. Early adolescence is a time of greater peer group conformity (Hartup, 1983) and also a time when a low parent- high peer attachment might be more likely to lead to social deviancy (Cairns et al., 1988). The inclusion of other demographic variables such as grade point average would also assist in gaining a better understanding of factors affecting attitudes towards cheating. Longitudinal studies, such as Wellman \& Berkowitz's (1988) research on attachment patterns, would provide invaluable information concerning the consistency of attachment between parent and child and between child and peers. Attachment research has contributed volumes of cross-sectional findings which assist in making only noncausal inferences about the nature of attachment.

Although the self-report technique produces reliable and valid measures (Akers, Massey, Clarke. \& Lauer, 1983; Radosevich, Lana-Kaduce, Akers, \& Krohn, 1979), this research would be enhanced by reports from parents and peers, behavioral indexes, and 
information as to whether the respondent had ever engaged in cheating behaviors and to what extent. Unfortunately, the request to obtain ATCS scores by mailings from parent and peer was unsuccessful in this study. These data would have revealed whether the parent and peer had similar attitudes toward cheating as that of the respondent, thus providing a more lucid picture into the relationship between attachment and its influence on attitudes.

Despite these limitations, this study contributes to the on-going research of parent and peer attachment as well as expanding the research on potential factors influencing a college student's condemnation or tolerance of academic dishonesty. This study did not reveal information concerning the negative side effects of attachment and social support for this particular population of late adolescent college students; instead, the results of this study are supportive of those theories which focus on the negative side effects that the lack of attachment or limited attachment may cause( Bowlby, 1973, Ainsworth et al., 1978; Kobak \& Sceery, 1988). This study has provided additional information to the understanding of the positive, negative, or neutral effects of parent and peer attachment on the behavior and attitudes of an individual at a particular developmental stage, hopefully contributing to an improved understanding of attachment across the life-span. 


\section{REFERENCES}

Ainsworth, M. D. S., Blehar, M., Waters, E., \& Wall, S. (1978). Patterns of attachment. Hillsdale, N. J.: Erlbaum.

Ainsworth, M. D. S. (1989). Attachment beyond infancy. American Psychologist, 44. 709-716.

Akers, R, Massey, J., Clarke, W., \& Lauer, R. (1983). Are self-reports of adolescent deviance valid? Biochemical measures, randomized response, and the bogus pipeline in smoking behavior. Social Forces, 62, 234-251.

Antonucci, T. C. (1990). Social supports and social relationships. In R. H. Binstock, \& L. K. George (Eds.), Handbook of aging and the social sciences (pp. 105-126). New York: Academic Press.

Armsden, G. C., \& Greenberg, M. T. (1988). The Inventory of Parent and Peer Attachment: Individual differences and their relationship to psychological well-being in adolescents. Journal of Youth and Adolescence, 16, 427-454.

Armsden, G. C., McCauley, E., Greenberg, M. T., Burke, P. M., \& Mitchell, J. R. (1990). Parent and peer attachment in early adolescent depression. Journal of Abnormal Child Psychology, 18, 683-697.

Arnstein, R. (1980). The student, the family, the university, and the transition to adulthood. Adolescent Psychiatry, Vol. 8(pp. 160-172). Chicago: University of Chicago Press.

Baird, J. S., Jr. (1980). Current trends in college cheating. Psychology in the schools, 17. $515-522$.

Bartholomew, K., \& Horowitz, L. M. (1991). Attachment styles among young adults: 
A test of a four-category model. Journal of Personality and Social Psychology, 61, 226244.

Batgos, J., \& Leadbetter, B. J. (1994). Parental attachment, peer relations, and dysphoria in adolescence. In M. B. Sperling, \& W. H. Berman (Eds.), Attachment in adults: Clinical and developmental perspectives (pp. 155-178). Guilford Press: New York.

Bell, N. J., Avery, A. W., Jenkins, D., Feld, J., \& Schoenrock, C. J. (1985). Family relationships and social competence during late adolescence. Journal of Youth and Adolescence, 14, 109-119.

Bergston, V., Rosenthal, C., \& Burton, L. (1990). Families and aging: Diversity and heterogeneity. In R. H. Binstock, \& L. K. George (Eds.), Handbook of aging and the social sciences (pp. 263-287). New York: Academic Press.

Berndt, T. J. (1979). Developmental changes in conformity to peers and parents. Developmental Psychology, 15, 608-616.

Blain, M. D.. Thompson, J. M., \& Whiffen. V. E. (1993). Attachment and perceived social support in late adolescence: The interaction between working models of self and others. Journal of Adolescent Research, 8, 226-241.

Blos, P. (1967). The second individuation process of adolescence. Psychoanalytic Study of the Child, 12, 162-172.

Blustein, D. L., Walbridge, M. M., Friedlander, M. L., \& Palladino, D. E. (1991). Contributions of psychological separation and parental attachment to the career development process. Journal of Counseling Psychology, 38, 39-50. 
Boiven, M., Hymel, S., \& Bukowski, W. M. (1995). The roles of social withdrawal, peer rejection, and victimization by peers in predicting loneliness and depressed mood in childhood. Development and Psychopathology, 7, 765-785.

Bonjean, C. M., \& McGee, R. (1965). Undergraduate scholastic dishonesty: A comparative analysis of deviance and control systems. Social Science Quarterly, 65 , 285-296.

Bowers, W. J. (1964). Student dishonesty and its control in college. New York: Bureau of Apllied Social Research, Columbia University,

Bowlby, J. (1969). Attachment and loss. Vol. 1. Attachment. New York: Basic Books.

Bowlby, J. (1973). Attachment and loss. Vol. 2. Separation. New York: Basic Books.

Bradford, E., \& Lyddon, W. J. (1993). Current parental attachment: Its relation to perceived psychological distress and relationship satisfaction in college students. Journal of College Student Development, 34, 256-260.

Brack, G., Gay, M. F., \& Matheny, K. B. (1993). Relationships between attachment and coping resources among late adolescents. Journal of College Student Development, $\underline{34}, 212-215$.

Brennan, K. A., Shaver, P. R. , \& Tobey, A. E. (1991). Attachment styles, gender, and parental problem drinking. Journal of Social and Personal Relationships, 8, 451-466

Bretherton. I. (1985). Attachment theory: Retrospect and prospect:. In I. Bretherton, \& E. Waters (Eds.), Growing points in attachment theory and research. Monographs of the Society for Research in Child Development, 50 (1-2, Serial No. 209), 3-35.

Cairns, R. B., Cairns, B. D., Neckerman, H. J., Gest, S. D., \& Gariepy, J. (1988). 
Social networks and aggressive behaviors: Peer support or peer rejection? Developmental Psychology, 24, 815-823.

Calabrese, R. L., \& Cochran, J. T. (1990). The relationship of alienation to cheating among a sample of American adolescents. Journal of Research and Development in Education, 23, 65-71.

Chickering, A. W. (1969). Education and identity. San Francisco: Josey-Bass. Cohen, S., \& Wills, T. A. (1985). Stress, social support, and the buffering hypothesis. Psychological Bulletin, 98, 310-357.

Coie, J. D., Terry, R., Lenox, K, Lochman, J., \& Hyman, C. (1995). Childhood peer rejection and aggression as predictors of stable patterns of adolescent disorder. Development and Psychopathology, 7, 697-713.

Collins, N. L.. \& Reed, S. J. (1990). Adult attachment, working models, and relationship quality in dating couples. Journal of Personality and Social Psychology, 58, 644-663.

Corcoran, K. J. \& \& Rotter, J. B. (1986). Morality-conscience guilt scale as a predictor of ethical behavior in a cheating situation among college females. The Journal of General Psychology, 114. 117-123.

Covey, M. K.. Saladin, S., \& Killen, P. J. (1988). Self-monitoring, surveillance, and incentive effects on cheating. The Journal of Social Psychology, 129, 673-679.

Coyne, J. C., Wortman, C. B., \& Lehman, D. R. (1988). The other side of support: Emotional overinvolvement and miscarried helping. In E. Gottlieb (Ed.), Marshaling social social: Formats, processes, and effects (pp. 305-331). Beverly Hills, CA: Sage. 
Davis, S. F., Grover, C. A., Becker, A. H., \& McGregor, L. N. (1992). Academic dishonesty: Prevalence, determinants, techniques, and punishments. Teaching of Psychology, 19, 16-20.

Davis, S. F., \& Ludvigson, H. W. (1995). Additional data on academic dishonesty and a proposal for remediation. Teaching of Psychology, 22, 119-121.

Enker, M. S. (1987). Attitudinal and normative variables as predictors of cheating behavior. Journal of Cross-cultural Psychology, 18, 315-330.

Entwisle, D. R., \& Astone, N. M. (1994). Some practical guidelines for measuring youth's race/ethnicity and socioeconomic status. Child Development, 65, 1521-1540.

Erikson, E. (1958). Young Man Luther: A study in psychoanalysis and history. New York: W. W. Norton.

Fishbein, L. (1993). Curbing cheating and restoring academic integrity. The Chronicle of Higher Education, p. A52.

French, D. C.. Conrad, J., \& Turner, T. M. (1995). Adjustment of antisocial and nonantisocial rejected adolescents. Development and Psychopathology, 7, 857-874.

Furman, W., \& Buhrmester, D. (1992). Age and sex differences in perceptions of networks of personal relationships. Child Development, 63, 103-115.

Gardner, W. M., \& Melvin, K. B. (1988). A scale for measuring attitude toward cheating. Bulletin of the Psychonomic Society, 26, 429-432.

Gardner, W. M., Roper, J. T., Gonzalez, C. G., \& Simpson, R. G. (1988). Analysis of cheating on academic assignments. The Psychological Record, 38, 543-555.

Gewirtz, J. L. (1972). The role of stimulation in models for child development. In L. L. Dittman (Ed.), Early child care: The new perspectives (pp. 139-168). New York: 
Atherton Press.

Gillmore, M. R., Hawkins, J., Day, L. E., \& Catalano, R. F. (1992). Friendship and deviance: New evidence on an old controversy. Journal of Early Adolescence, 12, 80-95.

Greenberg, M. T., Siegel, J. M., \& Leitch, C. J. (1983). The nature and importance of attachment relationships to parent and peer during adolescence. Joumal of Youth and Adolescence, 12, 373-386.

Haines, V. J., Diekhoff, G. M., LaBeff, E. E., \& Clark, R. E. (1986). College cheating: Immaturity, lack of commitment, and the neutralizing attitude. Research in Higher Education, 25, 342-354.

Hagestad, G. O. (1982). Parent and child: Generations in the family. In T. M. Field, A. Huston, H. C. Quay, L. Troll, \& G. E. Finley (Eds.), Review of human development (pp. 485-499). New York: Wiley Interscience.

Hartup, W. W. (1983). Peer relations. In E. M. Hetherington (Ed.), Handbook of child psychology: Vol. 4. Socialization, personality, and social development (pp.103-196). New York: Wiley.

Hays, R. \& Oxley, D. (1986). Social network development and functioning during a life transition. Journal of Personality and Social Psychology, 50, 305-313.

Hazen, C., \& Shaver, P. (1987). Romantic love conceptualized as an attachment process. Joumal of Personality and Social Psychology, 52, 511-524.

Heller, K. (1979). The effects of social support: Prevention and treatment implications. In A. P. Goldstein, \& F. H. Kanifer (Eds.), Maximizing treatment gains: Transfer enhancement in psychotherapy (pp. 353-382). New York: Academic Press. 
Heller, K, \& Swindle, R. W. (1983). Social networks, perceived social support, and coping with stress. In F. D. Felner, L. A. Jason, J. Moritsugu, \& S. I. Farber (Eds.), Preventive psychology: Theory, research, and practice in community intervention (pp. 87-103). New York: Pergamon.

Hirschi, T. (1969). Causes of delinquency. Berkeley: University of California Press. Holahan, C. J., \& Moos, R. H. (1982). Social support and adjustment: Predictive benefits of social climate indices. American Journal of Community Psychology, 15. 403-415.

Homans, G. L. (1974). Social behavior (2nd ed.). New York: Harcourt Brace Jovanovich.

Houston, J. P. (1978). Curvilinear relationships among anticipated success, cheating behavior, temptation to cheat, and perceived instrumentality of cheating. Joumal of Educational Psychology, 70, 758-762.

Huss, M. T., Curnyn, J. P., Roberts, S. L., Davis, S. F., Yandell, L., \& Giordano, P. (1993). Hard driven but not dishonest: Cheating and the type A personality. Bulletin of the Psychonomic Society, 31, 429-430.

Jendrek. M. P. (1992). Students' reactions to academic dishonesty. Journal of College Student Development, 33, 260-272.

Kahn, R. L., \& Antonucci, T. C. (1980). Convoys over the life course: Attachment, roles, and social support. In P. B. Baltes, \& O. G. Brim (Eds.), Life span development and behavior: Vol. 3. (pp. 253-286). New York: Academic Press.

Kalish, R. A., \& Knudtson, F. W. (1976). Attachment versus disengagement: A life- 
span conceptualization. Human Development, 19, 171-181.

Karahenick, S. A., \& Srull, T. K. (1978). Effects of personality and situational variation in locus of control on cheating: Determinants of the "congruence effect." Journal of Personality, 46, 72-95.

Kenny, M. (1990). College seniors' perceptions of parental attachment: The value and stability of family ties. Journal of College Student Development, 31, 39-46.

Kenny, M. E., \& Donaldson, G. A. (1991). Contributions of parental attachment and family structure to the social and psychological functioning of first-year college students. Journal of Counseling Psychology, 38, 479-486.

Kenny, M. E.. \& Donaldson, G. A. (1992). The relationship of parental attachment and psychological separation to the adjustment of first-year college students. Journal of College Student Development, 33, 431-438.

Kobak, R.. R. \& Sceery, A. (1988). Attachment in late adolescence: Working models affect regulation. and representation of self and others. Child Development, 59, 135-146.

Kupersmidt. J. B., Burchinal, M. T., \& Patterson. C. J. ((1995). Developmental patterns of childhood peer relations as predictors of externalizing behavior problems.

Development and Pschopathology, 7, 825-843.

Lanza-Kaduce, L. \& Klug, M. (1986). Learning to cheat: The interaction of moraldevelopment and social learning theories. Deviant Behavior, 7, 243-259.

Lapsley, D. K. Rice. K.G., \& Fitzgerald, D. P. (1990). Adolescent attachment, identity, and adjustment to college: Implications for the continuity of adaption hypothesis. Journal of Counseling and Development, $68,561-565$.

Lapsley. D. K. Rice, K. G., \& Shadid, G. E. (1989). Adolescent health risk behaviors: 
Family stress andadolescent coping as critical factors. Family Relations, 34, 51-62.

Lemming, J. S. (1980). Cheating behavior, subject variables, and components of the internal-external scale under high and low risk conditions. Journal of Educational Research, 74, 83-87.

Levitt, M. J. (1991). Attachment and close relationships: A life span perspective. In J. L. Gewirtz \& W. F. Kurtines (Eds.), Intersections with attachment. Hillsdale, N. J.: Erlbaum.

Levitt. M. J., Coffman. S., Guacci-Franco, N., \& Loveless, S. (1992). Attachment relationships and life transitions: An expectancy model. In M.B. Sperling and W. H. Berman (Eds.), Attachment, assessment, and treatment. New York: Guilford.

Levitt, M. J., Silver, M. E., \& Guacci-Franco, N. (1993). Negative relationship experiences: The dark side of interpersonal relationships. Presented at the meeting of American Psychological Association, Toronto, August, 1993.

Levitt, M. J., Weber, R. \& Guacci, N. (1993). Convoys of social support: An intergenerational analysis. Psychology and Aging, 8, 323-326.

Levy, R. L. (1983). Social support and psychological disorder: A review. Journal of Community Psychology, 11, 3-21.

Licitra-Klecker, D. M. \& Waas, G. A. (1993). Perceived social support among highstress adolescents: The role of peers and family. Joumal of Adolescent Research, 8 , 381-402.

Liska, A. E. (1978). Deviant involement, associations and attitudes: Specifying the underlying causal structures. Sociology and Social Research, $63,73-88$. 
Lopez, F. G. \& Gover, M. R. (1993). Self-report measures of parent-adolescent attachment and separation-individuation: A selective review. Journal of Counseling \& Development, $71,560-569$.

Main, M., Kaplan, N., \& Cassidy, J. (1985). Security in infancy, childhood, and adulthood: A move to the level of representation. Monographs of the Society for Research in Child Development, 50, 66-104.

Maramak, S. \& Maline, M. B. (1993). Academic dishonesty among college students. Issues in Education. Office of Research, United States Department of Education, 3-14.

Maurer. J. (1982). Reported stress of college seniors as a function of gender and sex role orientation. (Report No. CG 016 789), ERIC Document Reproduction Service NO. ED 232 (095).

Michaels, J. E. \& Miethe, T. D. (1989). Applying theories of deviance to academic cheating. Social Science Quarterly, 70, 870-885.

Nada Raja. S.. McGee, R., \& Stanton, W. R. (1992). Perceived attachment to parents and peers and psychological well-being in adolescence. Journal of Youth and Adolescence. 21, $471-485$.

Pallidino, D. E., \& Bluestein, D. L. (1991, August). Contributions of family relationship factors to the identity formation process. Paper presented at the annual meeting of the American Psychological Association, San Fransisco, CA.

Perry, A. R., Kane, K. M., Bernesser, K. J., \& Spicker, P. T. (1990). Type A behavior.competitive academic-striving, and cheating among college students. Psychological Reports, 66, 459-465.

Procidano. M. E. \& Heller, K. (1983). Measures of perceived social support from 
friends and from family: Three validative studies. American Journal of Community Psychology, 11, 1-24.

Quintana, S. M. \& Lapsley, D. K. (1987). Adolescent attachment and ego identity: A structural equation approach to the continuity of adaption. Journal of Adolescent Research, 2, 393-409.

Radosevich, M., Lanza-Kaduce, L., Akers, R., \& Krohn, M. (1979). The sociology of adolescent drug and drinking behavior: A review of the state of the field: Part I. Deviant Behavior, 1, 15-35.

Roig, M. \& Neaman, M. W. (1994). Alienation, learning or grade orientation, and achievement as correlates of attitudes toward cheating. Perceptual and Motor Skills, 78, 1096-1098.

Rook, K. S. (1984). The negative side of social interaction: Impact on the psychological well-being. Journal of Personality and Social Psychology, 46, 1097-1108.

Rothbard. J. C.. \& Shaver, P. R. (1994). Continuity of attachment across the life span. In M. B. Sperling, \& W. H. Berman (Eds.), Attachment in adults: Clinical and developmental perspectives (pp. 31-71). Guilford Press: New York.

Ryan, R. M. \& Lynch. J. H. (1989). Emotional autonomy versus detachment: Revisiting the vicissitudes of adolescence and young adulthood. Child Development,60, 340-356.

Schab. F. (1991). Schooloing without learning: Thirty years of cheating in high school. Adolescence, 26, 839-848.

Schulz. R. \& Rau. M. T. (1985). Social support through the life course. In S. Cohen 
\& S. L. Syme (Eds.), Social support and health (pp. 129-149). San Diego, CA: Academic Press.

Sebald, H. (1989). Adolescents' peer orientation: Changes in the support system during the past three decades. Adolescence, 24, 937-945.

Smith, T. E. (1976). Push versus pull : Intra-family versus peer group variables as possible determinants of adolescent orientation toward parents. Youth and Society, 8, $5-26$.

Sroufe. L. A. (1983). Infant caregiver attachment and patterns of adaptation in preschool: The roots of maladaptation and competence. In M. Perlmutter (Ed.), Minnesota symposium on child psychology (Vol.16, pp. 41-81). Hillsdale, NJ: Erlbaum.

Steinberg, L. \& Silverberg, S. B. (1986). The vicissitudes of autonomy in early adolescence. Child Development, 57, 841-851.

Stevens, G. E. ( 1984). Ethical inclinations of tomorrow's citizens; Actions speak louder? Joumal of Business Education, January, 147-152.

Takahashi. K. (1990). Affective relationships and their lifelong development. In P. B. Baltes. D. L. Featherman. \& L. R. Sherrod (Eds.), Life span development and behavior. Vol. 10 (pp. 1-22). Hillsdale, N.J. : Erlbaum.

Thibaut. J. \& Kelly, H. H. (1959). The social psychology of groups. New York: Wiley.

Troll. L. \& Smith, J. (1976). Attachment through the life span: Some questions about dyadic bonds among adults. Human Development, 19, 156-170.

Vitro. F. T. (1969). The effects of probability of test success, opportunity to cheat and 
test importance on the incidence of cheating. Unpublished doctoral dissertation, University of Iowa.

Ward, D. S. (1986). Self-esteem and dishonest behavior revisited. The Journal of Social Psychology, 126, 709-713.

Weiss. R. S. (1982). Attachment in adult life. In C. Parkes \& J. Stevenson-Hinde (Eds.), The place of attachment in human behaviour (pp. 171-184). New York: Basic Books.

Winemiller, D. R.. Mitchell, M. E., Sutliff, J., \& Cline, D. J. (1993). Measurement strategies in social support: A descriptive review of the literature. Journal of Clinical Psychology, 49, 638-647.

Winston, A. S. (1975). Experimental analysis of cheating and admissions of cheating in a classroom setting. Dissertation Abstracts, 36, 2508.

Wolchik, S. A. Ruehlman, L. S. Braver, S. L., \& Sandler, I. N. (1989). Social support of children of divorce: Direct and stress buffering effects. American Journal of Community Psychology, 17, 485-501.

Youniss, J. \& Smoller, J. (1985). Adolescents' relations with mothers, fathers, and friends. Chicago: University of Chicago Press. 
Table 1

Number and Percent of Students at 3 Levels of Parent Attachment by 3 Levels of

\section{Peer Attachment}

\begin{tabular}{lccc}
\hline & & Peer attachment \\
\cline { 3 - 4 } & Low & Medium \\
& $n(\%)$ & $\begin{array}{c}\text { High } \\
n(\%)\end{array}$ & $n(\%)$ \\
Parent attachment & $41(14)$ & $38(13)$ & $16(06)$ \\
Low & $41(14)$ & $30(11)$ & $24(08)$ \\
High & $17(06)$ & $28(10)$ & $48(17)$ \\
\hline
\end{tabular}


Table 2

Means and Standard Deviations of ACTS by Attachment Category

\begin{tabular}{|c|c|c|c|}
\hline & \multicolumn{2}{|c|}{ Parent attachment } & \multirow[b]{2}{*}{ Low } \\
\hline & High & Medium & \\
\hline & $\mathrm{M}(\mathrm{SD})$ & $\mathrm{M}(\mathrm{SD})$ & $\mathrm{M}(\mathrm{SD})$ \\
\hline \multicolumn{4}{|c|}{ Peer Attachment } \\
\hline High & $5.06(11.29)$ & $5.67(9.39)$ & $9.19(12.57)$ \\
\hline Medium & $8.46(9.07)$ & $6.70(8.93)$ & $2.68(10.62)$ \\
\hline Low & $5.82(10.09)$ & $5.90(8.31)$ & $1.93(9.01)$ \\
\hline
\end{tabular}


Table 3

Correlation Coefficients for Parent Attachment and Peer Attachment and ATCS

Attachment Variables $\quad$ ATCS Score

Parent Attachment $\quad 05$

Parent Trust $\quad .02$

Parent Communication $\quad .01$

Parent Alienation $\quad-.13 * *$

Peer Attachment $\quad .11^{*}$

Peer Trust $\quad .10$

Peer Communication $\quad .06$

Peer Alienation $\quad-.11^{*}$

Note. ${ }^{*} \mathrm{p}=.07^{* *} \mathrm{p}=.03$ 
Table 4

Multiple Regression of Variables for ATCS

Variable

$\beta \quad$ r

$\mathrm{r}^{2} \quad$ Fchange

Demographic Variables

Living at home

Hispanic-American

European-American

Male

Born in the United States

Attachment Variables

Low parent attachment

High peer attachment

Low parent-high peer attachment
$-.01$

$-.01$

.00

$-.10$

$-.09$

. .02

$-.02$

$-.10 \quad-.10$

.11

.11

$.01 *$

.00

.01

.01

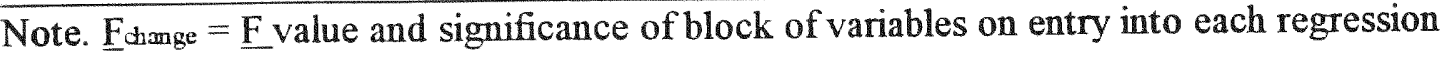
equation. ${ }^{*} \mathrm{p}<.08 * * \mathrm{p}<.01 * * * \mathrm{p}<.001$.

\section{$4.82 * *$}

$\begin{array}{lll}-.28 & -.20 & .04^{* * *} \\ -.05 & -.05 & .00\end{array}$

16

$.03^{* *}$ 


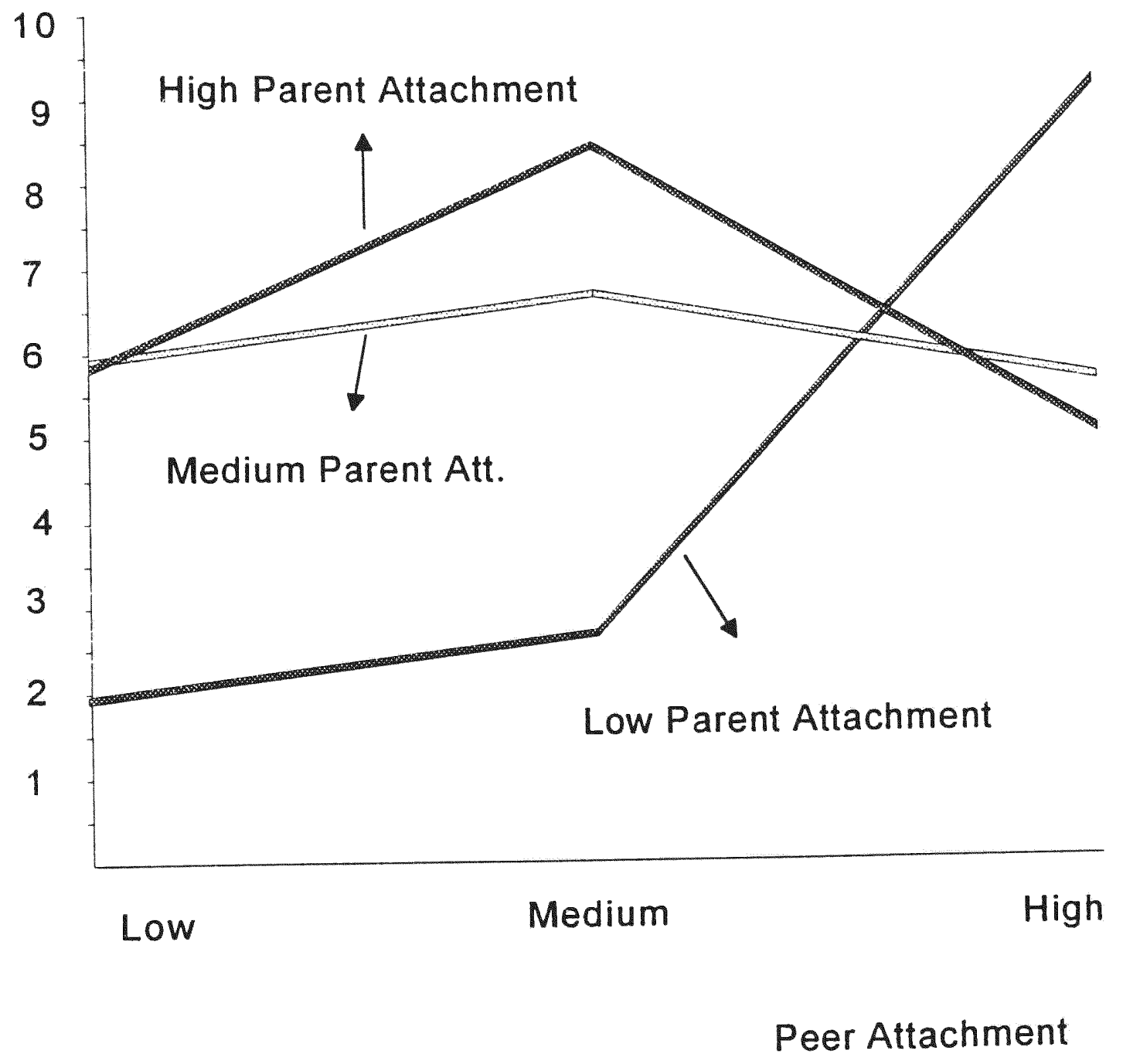


Appendix A

Please enter your three digit identification number here

Please look over the five choices below and then select the choice you feel best describes your relationship with your parent/parents. Place the number on the line to the left of the statements.

1--almost always or always true

2--often true

3--sometimes true

4--seldom true

5--almost never or never true

\section{SECTION I}

1. My parents respect my feelings.

2. I feel my parents are successful as parents.

3. I wish I had different parents.

4. My parents accept me as I am.

5. I have to rely on myself when I have a problem to solve.

6. I like to get my parents' point of view on things I'm concerned about.

7. I feel it's no use letting my feelings show.

8. My parents sense when I'm upset about something.

9. Talking over my problems with my parents makes me feel ashamed or foolish.

10. My parents expect too much out of me.

11. I get upset easily at home.

12. I get upset a lot more than my parents know about.

13. When we discuss things, my parents consider my point of view.

14. My parents trust my judgment.

15. My parents have their own problems, so I don't bother them with mine. 
16. My parents help me to understand myself better.

17. I tell my parents about my problems and troubles.

18. I feel angry with my parents.

19. I don't get much attention at home.

20. My parents encourage me to talk about my difficulties.

21. My parents understand me.

22. I don't know who I can depend on these days.

23. When I'm angry about something, my parents try to be understanding.

24. I trust my parents.

25. My parents don't understand what I'm going through these days.

26. I can count on my parents when I need to get something off my chest.

27. I feel that no one understands me.

28. If my parents know something is bothering me, they ask me about it.

Please enter your three digit identification number here

\section{SECTION II}

Please look over the five choices below and select the choice you feel best describes your relationship with your friend/peers. Place the number on the line to the left of the statement.

1--almost always or always true

2--often true

3--sometimes true

4--seldom true

5--almost never or never true 
1. I like to get my friends' point of view on things I'm concerned about.

2. My friends sense when I'm upset about something.

3. When we discuss things, my friends consider my point of view.

4. Talking over my problems with my fiends makes me feel ashamed or foolish.

5. I wish I had different friends.

6. My friends understand me.

7. My friends encourage me to talk about my difficulties.

8. My friends accept me as I am.

9. I feel the need to be in touch with my friends more often.

10. My friends don't understand what I'm going through these days.

11. I feel alone or apart when I am with my friends.

12. My friends listen to what I have to say.

13. I feel my friends are good friends.

14. My friends are fairly easy to talk to.

15. When I am angry about something, my friends try to be understanding.

16. My friends help me to understand myself better.

17. My friends are concerned about my well-being.

18. I feel angry with my friends.

19. I can count on my friends when I need to get something off my chest.

20. I trust my friends.

21. My friends respect my feelings.

22. I get upset a lot more than my friends know about.

23. It seems as if my friends are irritated with me for no reason. 
24. I tell my friends about my problems and troubles.

25. If my friends know something is bothering me, they ask me about it. 
Appendix B

Enter your three digit identification number here

The Attitude Toward Cheating Scale

Rate each item below with the appropriate number

1 for strongly agree

2 for agree

3 for undecided(or if you don't understand the statement)

4 for disagree

5 for strongly disagree

1. If during a test one student is looking at another student's answer sheet, the teacher should not point this out until after class because it might embarrass the student.

2. If a teacher sees a student cheating, it is just the teacher's word against the student's, unless the student admits he or she was cheating.

3. Cheating on college tests is morally wrong.

4. If during a test two students are looking at each other's answer sheet and talking, the teacher should not assume they are cheating.

5. Some sororities and fraternities keep files of old tests to use in predicting what will be on future tests. This is cheating.

6. Only the student knows if he or she was cheating; therefore, no decision should be made until the student is asked whether he or she cheated.

7. If a student says he or she did not cheat and gives some explanation for his or her behavior, only an unfair teacher would penalize the student.

8. If a term paper includes a series of exact statements from a book which is not listed as a source, the teacher must assume that the student intentionally plagiarized.

9.It is cheating to ask another student(from an earlier section) "What was on on the test?"

10.If a student is offered a copy of a stolen test, the offer should be refused.

11.If a student is caught cheating, that student should plead innocent and force the school to prove the accusation.

12. When a student who denies cheating is found guilty, the student should receive additional punishment for lying.

13.If a student accused of cheating admits having cheated, the punishment should be reduced to reward honesty.

14.A student who hands in a purchased term paper should be expelled from school. 
15.If a teacher leaves the room during a test, the teacher is in effect okaying cheating. 16. Most students who don't cheat are just afraid of getting caught.

17.All tests should be open book, because in real life we can always look in the book.

18.A student who sees another student cheating and reports it should refuse to identify the cheater.

19.If over half the class is cheating on an assignment, the others are justified in cheating also.

20. Students should report by name anyone seen cheating.

21. Students are justified in cheating if the teacher's grading system is unfair.

22. Studying usually doesn't result in a better grade.

23.Most students who cheat are unethical people.

24.Making up an excuse in order to withdraw from a course to avoid failing is cheating.

25. Smart students make good grades without really having to study.

26. The whole purpose of going to college is to get a degree.

27. Students who cheat don't learn as much as others. 